\title{
Compressive Strength of Geopolymer Concrete: Influence of Size of Gravel
}

\author{
Ernesto J. Guades, Ph.D., Otilia G. Taduyo, and Marlon D. Sobreviga
}

\begin{abstract}
This paper presents an investigation on the behavior of the geopolymer concrete under compressive loading. Particularly the effect of the size of gravel is highlighted. Compressive tests have been carried out on a $100 \mathrm{~mm}$ x $200 \mathrm{~mm}$ cylindrical specimen using a compression testing machine. The specimens were cured at an ambient temperature and in oven at $60^{\circ} \mathrm{C}$. The result showed that a compressive strength of up to $45 \mathrm{MPa}$ can be obtained from the current mixture of geopolymer concrete. Gravel size ranging from 12.5 - $25 \mathrm{~mm}$ offered a maximum compressive strength. It was observed that the size of the coarse aggregates does not affect the trend that oven-cured specimen has higher compressive strength values than ambient cured specimens.
\end{abstract}

Keywords-Geopolymer concrete, Compressive strength, Coarse aggregates, Oven-cured specimen.

\section{INTRODUCTION}

$\mathrm{T}$ HE construction industry has been traditionally used cement in binding component materials to form concrete. However, its production poses environmental issues due to the large amount of greenhouse gas released into the atmosphere [1]. A solution is to use fly ash as a replacement of cement in binding the component materials in concrete (i.e., geopolymer concrete). Geopolymer is an inorganic alumino-silicate compound, synthesized from by-product materials such as fly ash that are rich in silicon and aluminium [2]. It has superior performance in terms of sulfate attacks resistance [3] and fire [4]. Concrete is a hardened mixture of component materials including coarse aggregates (gravel). Accordingly, the compressive strength of concrete depends primarily on several factors including the size of gravel used. A number of studies on the effect of aggregates on concrete had been already undertaken [5-6]. These studies however focused on the influence of coarse aggregate size on the compressive strength of cement-based concrete. Therefore there is a need to characterize its effect on the compressive strength of fly ash-based concrete. This has been the motivation of conducting the present study.

Ernesto J. Guades, Ph.D. is with the Northwest Samar State University, Calbayog City, Samar, Philippines.

Otilia G. Taduyo is with the Northwest Samar State University, Calbayog City, Samar, Philippines.

Marlon D. Sobreviga is with the Northwest Samar State University, Calbayog City, Samar, Philippines.

\section{MATERIALS AND METHODS}

Class F dry fly ash conforming ASTM C-618 specification obtained from Pozzolanic Philippines was used in casting the specimen. The alkaline liquid used for geopolymerization is a combination of sodium hydroxide $(\mathrm{NaOH})$ and sodium silicate $\left(\mathrm{Na}_{2} \mathrm{SiO}_{3}\right)$ that is commercially available. On the other hand, the fine aggregate (sand) used is clean dry river sand that passes through a $2.00-\mathrm{mm}$ sieve (No. 10) and retained on a $0.475-\mathrm{mm}$ (No. 40) sieve.

The coarse aggregate considered in this study has roundedtextural shape. The biggest size of gravel is $50 \mathrm{~mm}$ whilst the smallest size under this study is $12.5 \mathrm{~mm}$ (Fig. 1). Three ranges of gravel sizes were adopted in the study; M1 (12.5 $25 \mathrm{~mm})$; used in M2 (25 - 37.5 mm); and used in M3 (37.5 $50 \mathrm{~mm}$ ). In order to get this size range, an improvised sieve was fabricated from steel wire mesh.

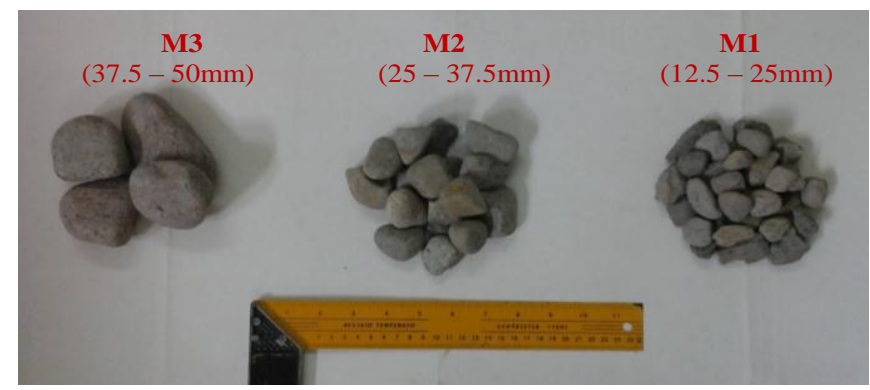

Fig. 1 Rounded aggregates used in the study

Table 1 shows the details of the mixed proportion (by mass) adopted in this study. It should be noted that these mixtures are adopted from the work of Joseph and Mathew [7]. The ratio of alkali to fly ash is 0.55; ratio of $\mathrm{Na}_{2} \mathrm{SiO}_{3} / \mathrm{NaOH}$ is 2.5 ; ratio of water to geo-polymer solid is 0.25 ; ratio of fine aggregate to total aggregate of 0.35 ; geopolymer concrete with total aggregate content of $70 \%$ by volume; and $\mathrm{NaOH}$ molarity 10 were applied. All calculations of the material contents were done in an Excel spread sheets.

The fly ash, aggregate and alkaline solutions were mixed manually. The fresh fly-ash based concrete was casted into cylindrical moulds $(100 \mathrm{~mm}$ x $1200 \mathrm{~mm})$ immediately after mixing. Two curing methods (i.e., ambient and oven-cured) were applied in the study. Ambient curing was performed by storing the specimens at a room temperature of $28-30^{\circ} \mathrm{C}$ for 28 days. For oven-cured specimens, they were placed in the 
oven at $60^{\circ} \mathrm{C}$ for 24 hours, removed, and cured for 28 days.

TABLE I

MIX PROPORTION OF GEOPOLYMER CONCRETE (BY MASS)

\begin{tabular}{|c|c|c|c|c|}
\hline & Mixture & M1 & M2 & M3 \\
\hline & ine/Fly Ash Ratio & 0.55 & 0.55 & 0.55 \\
\hline & $\begin{array}{l}\text { eve Designation } \\
\text { e Size Range (mm) }\end{array}$ & $\begin{array}{c}1 / 2 "-1 " \\
(12.5-25)\end{array}$ & $\begin{array}{l}1 "-11 / 2 " \\
(25-37.5)\end{array}$ & $\begin{array}{l}11 / 2 ”-2 ” \\
(37.5-50)\end{array}$ \\
\hline & Fly Ash & $16.67 \%$ & $16.67 \%$ & $16.67 \%$ \\
\hline & Fine Aggregates & $24.50 \%$ & $24.50 \%$ & $24.50 \%$ \\
\hline$\%$ by & Coarse Aggregates & $45.50 \%$ & $45.50 \%$ & $45.50 \%$ \\
\hline Mrass & Sodium Hydroxide & $2.62 \%$ & $2.62 \%$ & $2.62 \%$ \\
\hline & Sodium Silicate & $6.54 \%$ & $6.54 \%$ & $6.54 \%$ \\
\hline & Added Water & $4.17 \%$ & $4.17 \%$ & $4.17 \%$ \\
\hline & 11 Percentage (\%) & $100 \%$ & $100 \%$ & $100 \%$ \\
\hline
\end{tabular}

Additionally, two mixtures of cement-based concrete were prepared for comparison. A mixture of 1:2:3 (cement, sand, and water by volume; respectively) and a mixture similar to that of a geopolymer concrete using an aggregate of size ranges from $12.5-25 \mathrm{~mm}$ (water proportion similar to that of alkaline activator). They were labelled as Cement 1:2:3 and Cement M1; respectively. Both were stored and cured at a room temperature of $28-30^{\circ} \mathrm{C}$ for 28 days. A total of 3 replicates were prepared for each mixture of fly ash-based and cement-based concrete specimens. Figure 2 displays the casted geopolymer specimens.

For the evaluation of compressive strength, all cylinder specimens were subjected to test using a $2000 \mathrm{kN}$-capacity compressive testing machine under ASTM C873M standard. Moreover, snap shots of the specimen under testing were obtained to document its failure mode. Figure 3 shows the compressive testing machine and the test set-up of the study.

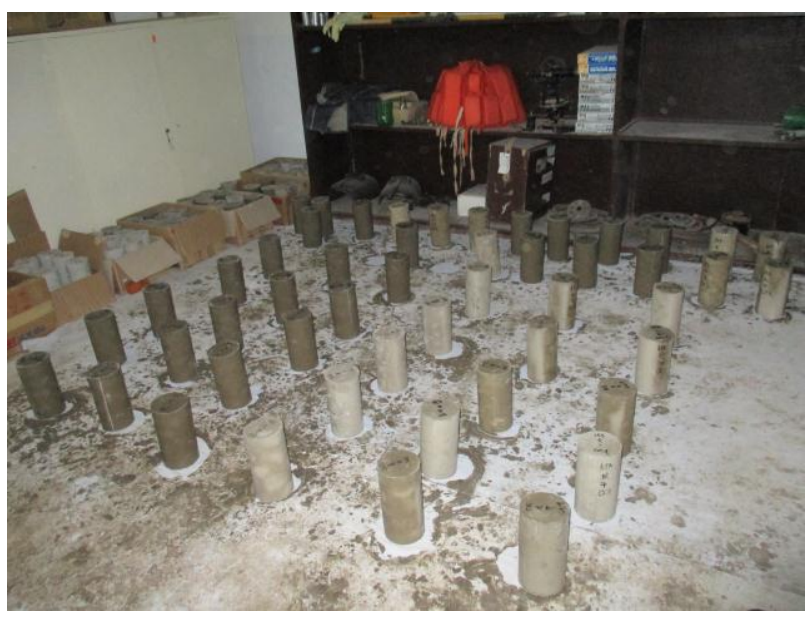

Fig. 2 Casting of geopolymer concrete specimens
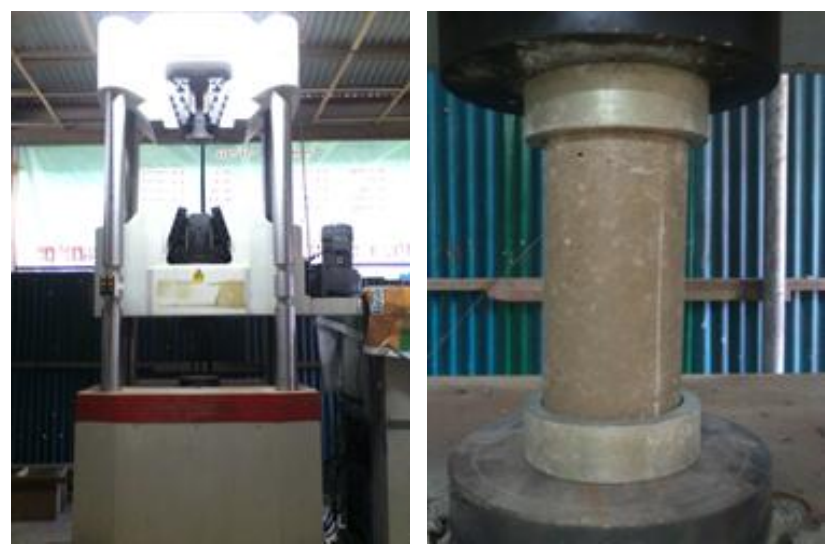

Fig. 3 Compressive test set-up

\section{EXPERIMENTAL RESULTS AND DISCUSSION}

\section{A. Data on the Compressive Testing}

Table 2 summarizes the results obtained from the compressive testing for fly ash-based concrete tested at varying particle size of gravel with the compressive strength. The value of the compressive strength of cement-based concrete is also included in the table. It should be noted that $\mathrm{AC}$ and $\mathrm{OC}$ in the specimen label ambient cured and oven cured; respectively. Moreover, the values indicated in the table are the average value obtained from three tested samples. It can be observed that the compressive strength of the fly ash-based concrete specimen tested is in the range of 23 to $34 \mathrm{MPa}$ for ambient-cured whilst the value for ovencured specimen is in between 29 to $45 \mathrm{MPa}$. In the case of cement-based concrete, the value of the compressive strength at 28 days curing is in the range of $6 \mathrm{MPa}$ to $16 \mathrm{MPa}$.

TABLE II

SUMMARY OF COMPRESSIVE STRENGTH OF TESTED CONCRETE SPECIMENS

\begin{tabular}{|l|c|}
\hline \multicolumn{1}{|c|}{ Specimen Label } & $\begin{array}{c}\text { Ave. Comp. Strength, MPa } \\
\text { (28 days) }\end{array}$ \\
\hline M1-AC & 33.63 \\
\hline M2-AC & 28.42 \\
\hline M3-AC & 22.75 \\
\hline M1-OC & 44.98 \\
\hline M2-OC & 38.89 \\
\hline M3-OC & 28.93 \\
\hline Cement M1 & 5.67 \\
\hline Cement 1:2:3 & 15.48 \\
\hline
\end{tabular}

\section{B. Effect on the Variation of Particle Size}

Fig. 4 shows the graph describing the effect of varying the particle size of gravel with the compressive strength of the tested specimens. It should be noted that the values used in 


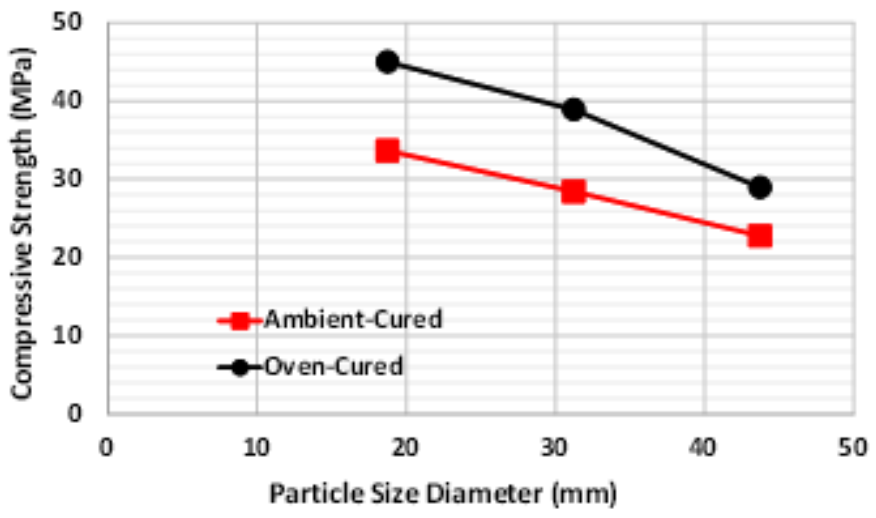

Fig. 4 Compressive test set-up

plotting the data point in the abscissa is taken by averaging the lower and upper limits (mean size) of the particle size range. As can be observed from the curve, generally the compressive strength decreases with increasing mean size of the coarse aggregates. This phenomenon can be explained by two notable reasons. First, bigger size aggregates generates wider aggregate-paste interface. This inter-facial zone becomes a weak zone whereby cracking will first occur [8]. Larger cracks may form at the interface, and they can interact easily with paste cracks as well as other interfacial cracks resulting in the reduction of the compressive strength. Second, internal bleeding occurs when water gets trapped on the underside of the bigger sized aggregate. This result in the formation of voids when the trapped water evaporates thus is decreasing the strength of the concrete. It was observe that the mean particle size of $18.75 \mathrm{~mm}$ provides the highest value of the compressive strength for specimen cured in an ambient temperature. This trend can be also observed in the specimens cured at ambient temperature and at $60^{\circ} \mathrm{C}$ (oven-cured).

\section{Effect on the Variation of Particle size with Curing Method}

Fig. 5 shows the curve describing the relationships of the gravel particle size with the method of curing. The figure shows that in all particle size, the compressive strength of an oven cured specimens reacted well as compared to the ambient cured specimens. This indicated that time of curing plays an essential role in achieving the compressive strength of fly ash-based concrete. According to Nagral et al. [9], this was because polymerization process increases with increase in the temperature and at a high temperature whereby the $2 \mathrm{D}$ polymer chains are converted into 3D-polymer chain with strong bond. Consequently, the increase in temperature results in increase in the rate of strength development. This result has been observed by several researchers [10-12] in which the compressive strength of fly-ash based specimen cured at higher temperature demonstrated higher value than when it is cured in an ambient condition.

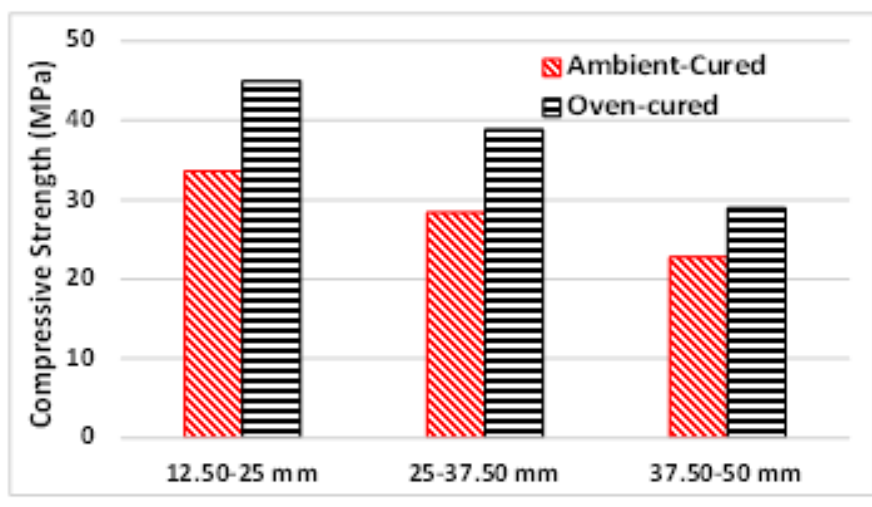

Fig. 5 Ambient versus oven-cured specimens

\section{Failure Mode of the fly ash-based geo-polymer concrete}

Fig. 6 displays the failure observed for geo-polymer concrete when it is subjective to compressive loading. Generally all of the failure types seen in the geo-polymer concrete are similar to the failure types of a typical cementbased concrete specimen tested in compression. Few of the samples failed initially by crushing of concrete in the compression face. On the other hand, cracking along the length of the specimen were also observed as a result of splitting due to the development of tensile forces. Accordingly, most of the specimens failed due to the presence of shear stress resulting in the collapse of the tested specimen (Figures 6a and 6b). The typical failure mode of the tested specimen is splitting, shear, columnar and conical type of failure. These types of failure were also observed in cementbased concrete when tested under compression loading.

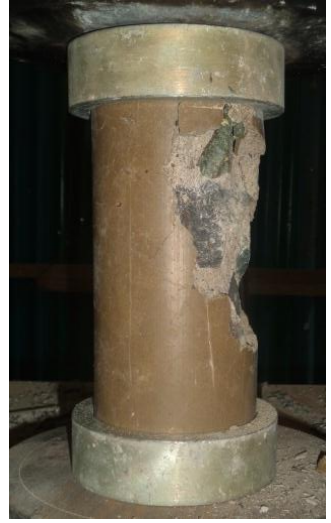

a. Shear

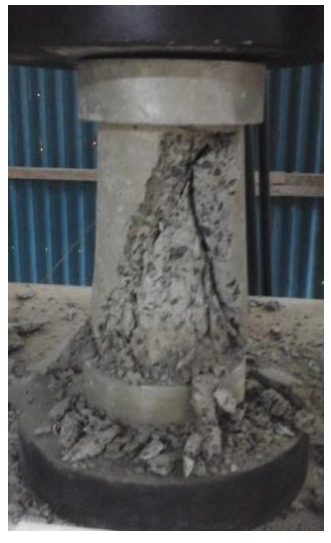

b. Cone and Shear
Fig. 6 Typical failure of tested geo-polymer concrete specimen

\section{E. Comparison of the fly ash-based and cement-based concrete}

The comparison of the compressive strengths of fly ash and cement-based concrete is displayed in Figure 7. It should be noted that both fly ash-based and cement-based specimens used in the comparisons utilized round-shape coarse aggregates cured under ambient temperature for 28 days. As reflected in the figure, the compressive strength of specimen 
Cement 1:2:3 is around 15.5 MPa whilst for specimen Cement M1 is 5.7 MPa. The result showed that the fly ashbased concrete exhibited higher compressive strength than the cement-based concrete. The value of the fly-ash based concrete exhibited more than two (2) times higher than the cement-based specimen at a mixture of 1:2:3. On the other hand, the compressive strength of the fly ash-based concrete is 6 times bigger than the specimen Cement M1. From this result, it can be deduced that geopolymer concrete has superior performance in terms of compressive strength as compared with its cement-based counterpart. Though the former offered better strength performance than the latter, is was observed that their mode of failure is almost identical as mentioned previously.

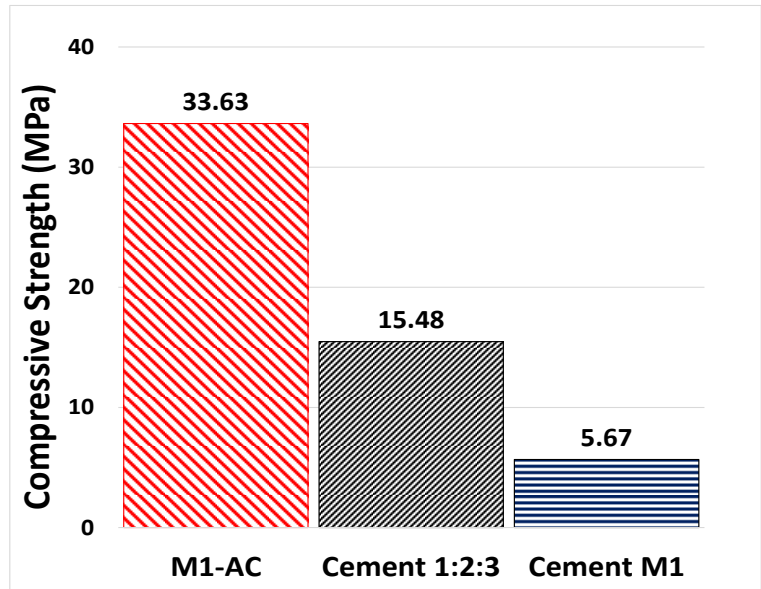

Fig. 7 Comparison between fly ash-based and cement-based concrete

\section{CONCLUSIONS}

This paper presents the experimental investigation on the influence of size of gravel on the compressive strength of geopolymer concrete. Compressive test was carried on a 100 $\mathrm{mm}$ x $200 \mathrm{~mm}$ cylindrical specimen using a compression testing machine. The following is the conclusions of the study. The typical failure mode of the tested specimen is splitting, shear, columnar and conical type of failure. It was found that the size of the coarse aggregates used in the fly ash-based concrete that offered a maximum compressive strength is in the range of $12.5-25 \mathrm{~mm}$. It was observed that the size of the coarse aggregates does not affect the trend that oven-cured specimen has higher compressive strength values than ambient cured specimens. Furthermore, the compressive strength of the fly ash-based concrete is comparably higher than the cement-based concrete by up to 6 times.

\section{ACKNOWLEDGMENT}

The authors would like to thank the support of the Northwest Samar State University for financing this study. Acknowledgement is also given to R.V. Construction for providing the aggregates; Engr. Alvin A. Lopez, Engr. Lendon D. Rivero and the first author's thesis advisee for their assistance in the conduct of the tests.

\section{REFERENCES}

[1] Hardjito D, Wallah SE, Sumajouw DMJ, and Rangan BV, "Factors influencing the compressive strength of fly ash based geopolymer concrete" Civil Engineering Dimension, Volume 6, P 88-93, 2004.

[2] Davidovits J., "Chemistry of Geopolymeric Systems", Terminology, Geopolymer '99 International Conference. France. 1999.

[3] Wallah SE, Hardjito D, Sumajouw DMJ and Rangan BV, "Sulfate and acid resistance of fly ash-based geopolymer concrete". In: Proceedings Australian Structural Engineering Conference, Newcastle, Australia, 2005.

[4] Kong DLY and Sanjayan JG, "Damage behavior of geopolymer composites exposed to elevated temperatures", Cement and Concrete Composites, Vol. 30, P 986-991, 2008. https://doi.org/10.1016/j.cemconcomp.2008.08.001

[5] Salau MA and Busari AO. (2015). Effect of Different Coarse Aggregate Sizes on the Strength Characteristics of Laterized Concrete. Materials Science and Engineering. Vol. 96, P 1-8. https://doi.org/10.1088/1757-899x/96/1/012079

[6] Hassan $\mathrm{N}$ and Mohammed $\mathrm{AB}$, "Effect and composition of maximum particle size of coarse aggregates on the compressive strength of normal concrete", Journal of Engineering and Applied Scientific Research, Vol. 6, No 2, P 46-56, 2004.

[7] Joseph B and Matthew G, "Influence of aggregate content on the behavior of fly ash based geopolymer concrete", Scientia Iranica; Vol 19, No 5, P 1188-1194, 2012. https://doi.org/10.1016/j.scient.2012.07.006

[8] Garrison F., "The concrete mix design", Civil Engineering and Construction Materials, Vol. 5, P 55-106, 2007.

[9] Nagral MR, Ostwal T and Chitawadagi MV, "Effect Of Curing Temperature And Curing Hours On The Properties Of Geo-Polymer Concrete", International Journal of Computational Engineering Research, Vol, 4, Issue 9, P 1-11, 2014.

[10] Thampi T, Sreevidya V and Venkatasubramani R., "Strength Studies on Geopolymer Mortar for Ferro Geopolymer Water Tank", International Journal of Advanced Structures and Geotechnical Engineering, ISSN 2319-5347, Vol. 03, No. 02, April 2014.

[11] Satpute MB, Wakchaure MR and Patankar SV, "Effect of Duration and Temperature of Curing on Compressive Strength of Geo-polymer Concrete", International Journal of Engineering and Innovative Technology, Vol 1, Issue 5, P 152-155, 2012.

[12] Patil AA., Chore HS and Dode PA, "Effect of curing condition on strength of geo-polymer concrete", Advances in Concrete Construction, Vol. 2, No. 1, P 29-37, 2014. https://doi.org/10.12989/acc.2014.2.1.029

Ernesto J. Guades. The first author obtained his Doctor of Philosophy (Structural Engineering) at the University of Southern Queensland (USQ) in Australia; Master of Engineering (Earthquake and Structural Engineering) at Saitama University, Japan and BS Civil Engineering at the Northwest Samar State University (NwSSU), Philippines. Dr. Guades is currently the Director of Research and Development Services and Lecturer in Structural Engineering at NwSSU. He is a reviewer of several international journals and an affiliate of scientific and professional groups. His research interests include characterization of geopolymer concrete for building and pavement applications and structural behavior of fiber-reinforced polymer (FRP) composite materials for timber/steel/concrete bridge rehabilitation. He can be contacted at the following address: Northwest Samar State University; Calbayog City, Samar, Philippines. 